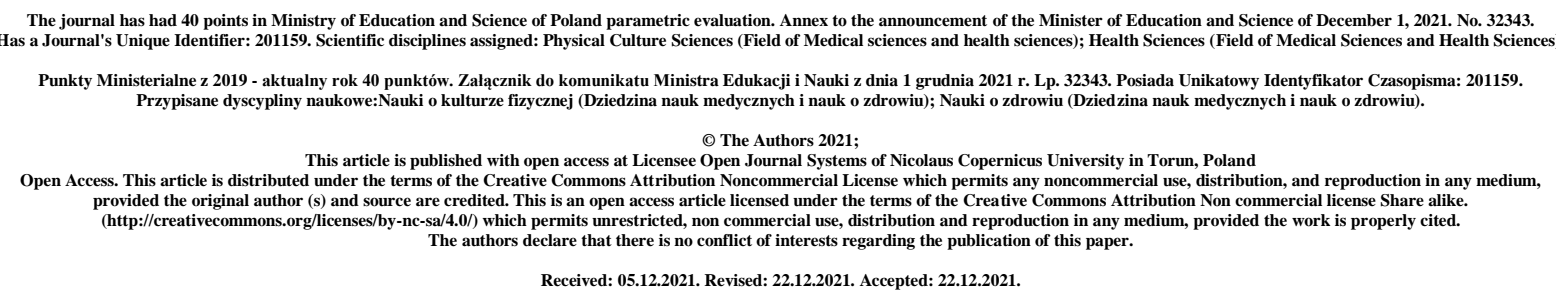

\title{
Pediatric neurology and telehealth before and during SARS-CoV-2 pandemic
}

\author{
Beata Golebiowska MD, $\mathrm{PhD}^{1}$ Maria Golebiowska $\mathrm{MD}^{2}$
}

1 beata.golebiowska@umlub.pl

https://orcid.org/0000-0002-1624-0063

golebiowska.maria8@gmail.com

https://orcid.org/0000-0002-8711-9834

\section{${ }^{1}$ Pediatric Neurology Department, III Chair of Pediatrics, Medical University of Lublin ${ }^{2}$ Student, Master in Global Bioethics, Anahuac University}

\section{SUMMARY}

\section{Introduction and purpose}

Telehealth, described as interventions using telecommunication to provide health care, health education, public health solutions and health administration, has been known in medicine for over 70 years. Until the year 2020, however, it has been utilized in a limited setting to provide long-distance care for individuals residing in areas lacking health facilities. SARS-CoV-2 pandemic shifted the priorities of healthcare system towards COVID-19 infections. Healthcare professionals had to face the greatest challenge to protect non-infected patients from COVID-19 transmission in hospitals. These aims resulted in the transition of non-essential and follow-up consultations to telemedicine in many countries. Since pediatric neurology requires frequent follow-up and multidisciplinary care, the purpose of our work is to determine the spectrum of use of telehealth in pediatric neurology before and during the pandemic. Secondly, we would like to discuss the differences of focus in tele-neurology for children patients between the pre-pandemic and during pandemic timeframes. 


\section{Current state of knowledge}

Within 171 articles of PubMED database, 36 substantial articles on the introduction of telehealth to pediatric neurology were included in the review. $30.5 \%$ of the articles have included the implementation of telemedicine before the pandemic, $69.5 \%$ of the articles discussed improvements made after the pandemic started. The spectrum of disorders and interventions considered for telehealth included epilepsy (particularly West Syndrome, introduction of ketogenic diet), cerebral palsy, rare diseases, teleneuropsychology and teleneurorehabilitation. Among major differences between pre-pandemic and pandemic research, increase in international cooperation and discussion of not only medical, but also scientific and academic impact of the pandemic could be noted.

\section{Conclusions}

Telehealth offers sustainable alternatives to many interventions which cannot be performed in-person during public health emergency such as SARS-CoV-2 pandemic. Despite high satisfaction of caregivers and healthcare professionals from the virtual visits, solutions are still far from perfection and need improvements to provide more support for the patients with various disorders, cover the concerns of privacy and confidentiality, as well as support patients from low-income and lack of electronic technology backgrounds.

Keywords: Telehealth; pediatric neurology; telemedicine; SARS-CoV2 pandemic

\section{INTRODUCTION}

Telehealth is described as interventions in healthcare which are using telecommunication for providing healthcare services, health education, public health solutions and health administration. Telemedicine is a part of telehealth which relates solely to medical interventions. [1] With current flourishing of the technology, being followed by the unfortunate necessity to limit the in-person services due to the pandemic, we see the rise of new branches related to particular telemedicine fields: telepsychology, telerehabilitation, teleneuromodulation etc. Telecommunication services can be delivered with synchronous (performed at the same time, such as eg. virtual visits) or asynchronous means (instructional videos for the patients, or videos of the symptoms from the patients).[2] It is often expanded to remote patient monitoring with various data storing devices, or mobile health, which uses prophylactic messages to targeted or general population. [3]

The idea of remote healthcare has been presented to the public in 1951 during New York's World Fair and introduced in practice with teleradiology in 1957. [1] Primarily, the aim for telehealth was to reach the communities, which did not have access to healthcare services, as well as to decrease the burden of caregivers and patients, such as the financial constraints due to transportation, loss of work days and school days. Particularily in pediatric neurology, with one of the highest shortages of specialists, telemedicine seems to be a great solution to reach geographically and economically disadvantaged populations. [4] Everything changed with the beginning of 2020, and the SARS-CoV-2 pandemic. The fear of unknown opponent lead healthcare to a defense strategy, protecting the unaffected from contracting the virus, and mobilizing the resources to help the infected. 
Continuous in-person provision of services for chronic diseases was impossible. It has been reported, that during 2003 SARS outbreak in China, lack of follow-up in group of epilepsy patients lead to lack of compliance with antiepileptic medication, and in result to worsening of the health status. [5] It has been confirmed during early stages of 2020 pandemic, that lack of in-person services affected patients' mental health, and resulted of deterioration of health condition due to lack of rehabilitation and follow-up consultation. [6] In these difficult times, the promising idea of telehealth resurfaced. Nowadays, it has been assessed that $92 \%$ of adults in USA between age 30-49 own a smartphone. [7] Additionally, with the necessity to provide remote education, remote labour and access to other remote services, the telemedical transition became inevitable.

\section{PURPOSE OF THE STUDY}

The aim of the study is to present the implementation of telehealth interventions in pediatric neurology, as well as to define the differences in application before and during SARS-CoV-2 pandemic.

\section{METHODS}

The comprehensive literature review has been performed firstly with identification of research crucial to telehealth in pediatric neurology via PubMed database, using keywords "pediatric neurology", "child neurology", "telemedicine", "telehealth". The eligibility criteria included literature published between 01.01.2006-01.12.2021, open access English literature of a high quality; exclusion criteria consisted of non-English literature and poor quality articles. Total 171 articles have been identified via initial search; after exclusion of 54 duplications, 65 non-related research articles have been excluded after abstract screening and 16 after full-text screening, leaving final 36 articles to be included in the analysis.

\section{DESCRIPTION OF THE STATE OF KNOWLEDGE}

Among 36 articles identified for further analysis, 30.5\% of the articles have included the implementation of telemedicine before the pandemic, $69.5 \%$ of the articles discussed improvements made after pandemic started.

\subsection{Pediatric neurology experiences before SARS-Cov-2 pandemic}

\begin{tabular}{|l|l|l|l|l|}
\hline $\begin{array}{l}\text { Study/ } \\
\text { Observ } \\
\text { ation }\end{array}$ & Country & Type of study & Study design & Advancements and Challenges \\
\hline $\begin{array}{l}\text { Craig } \\
\text { et al. }\end{array}$ & USA & $\begin{array}{l}\text { Neonatal } \\
\text { encephalopath } \\
\text { y diagnosis }\end{array}$ & $\begin{array}{l}\text { 26 patients teleconsulted due } \\
\text { to concerns for neonatal } \\
\text { encephaopathy while } \\
\text { neonatologist performed } \\
\text { Sarnat examination }\end{array}$ & $\begin{array}{l}\text { Reducing family separation } \\
\text { and unnecessary transfers } \\
\text { Community hospitals have } \\
\text { lack of further examinations to } \\
\text { confirm the diagnosis }\end{array}$ \\
\hline
\end{tabular}




\begin{tabular}{|c|c|c|c|c|}
\hline $\begin{array}{l}\text { Dayal } \\
\text { et al. }\end{array}$ & USA & $\begin{array}{l}\text { Effectiveness } \\
\text { of } \\
\text { telemedicine } \\
\text { vs in-person } \\
\text { visits }\end{array}$ & $\begin{array}{l}\text { Comparison of completion } \\
\text { of visits as well as patient } \\
\text { characteristics }\end{array}$ & $\begin{array}{l}57 \% \text { higher odds completion } \\
\text { in telemed group, telemedicine } \\
\text { patients - nonprivate } \\
\text { insurance, lower income and } \\
\text { lower education }\end{array}$ \\
\hline $\begin{array}{l}\text { Dayal } \\
\text { et al. }\end{array}$ & USA & $\begin{array}{l}\text { Hospital } \\
\text { utilization - } \\
\text { telemed vs in- } \\
\text { person visits }\end{array}$ & $\begin{array}{l}\text { Comparison of hospital } \\
\text { encounters in both groups }\end{array}$ & $\begin{array}{l}\text { Telemedicine had lower rate } \\
\text { of unplanned hospital } \\
\text { encounters (emergency visits } \\
\text { and admissions) } 5.7 \% \text { vs } \\
20.1 \% \text { in in-person visits }\end{array}$ \\
\hline $\begin{array}{l}\text { Gali et } \\
\text { al. }\end{array}$ & USA & $\begin{array}{l}\text { Introducing } \\
\text { pediatric tele- } \\
\text { neurology }\end{array}$ & $\begin{array}{l}61 \text { caregivers and pediatric } \\
\text { neurologists satisfaction, } \\
\text { measured positive outcomes }\end{array}$ & $\begin{array}{l}94 \% \text { parental and } 100 \% \\
\text { physician satisfaction, } \\
\text { reduction of out-pocket costs, } \\
\text { missed school and work hours }\end{array}$ \\
\hline $\begin{array}{l}\text { Gulati } \\
\text { et al. }\end{array}$ & India & $\begin{array}{l}\text { Accuracy of } \\
\text { telemed visits }\end{array}$ & $\begin{array}{l}\text { Comparison of pediatric } \\
\text { neurology fellow and } \\
\text { speciality nurse accuracy }\end{array}$ & $\begin{array}{l}\text { Lower identification of } \\
\text { atypical seizures, number of } \\
\text { breakthrough seizures, } \\
\text { subjective adverse events in } \\
\text { nurse consultation group }\end{array}$ \\
\hline $\begin{array}{l}\text { McCart } \\
\text { hy al. }\end{array}$ & USA & $\begin{array}{l}\text { Post- } \\
\text { concussive } \\
\text { symptoms } \\
\text { collaborative } \\
\text { care }\end{array}$ & $\begin{array}{l}\text { Comparison of post- } \\
\text { concussive } \\
\text { receiving collaborative vs } \\
\text { usual care }\end{array}$ & $\begin{array}{l}\text { Delivering CBT in the } \\
\text { convenience of the patient's } \\
\text { home, broadening the reach to } \\
\text { patients }\end{array}$ \\
\hline $\begin{array}{l}\text { Ragbee } \\
\text { r et al. }\end{array}$ & USA & $\begin{array}{l}\text { Juvenile } \\
\text { Neuronal } \\
\text { Ceroid } \\
\text { Lipofuscinosis } \\
\text { neuropsycholo } \\
\text { gical } \\
\text { assessment }\end{array}$ & $\begin{array}{l}4 \text { children with Batten } \\
\text { disease assessed with } \\
\text { cognitive tests: Wechsler } \\
\text { Intelligence Scale for } \\
\text { Children - Fourth edition14 } \\
\text { Similarities, Vocabulary, } \\
\text { Information, and Digit Span } \\
\text { subtests; Wide Range } \\
\text { Assessment of Memory and } \\
\text { Learning - Second edition15 } \\
\text { Story Memory subtest; } \\
\text { Verbal Fluency test }\end{array}$ & $\begin{array}{l}\text { Telemedicine beneficial for } \\
\text { assessment of rare diseases, } \\
\text { decreasing the psychosocial } \\
\text { and economic burdens }\end{array}$ \\
\hline
\end{tabular}




\begin{tabular}{|c|c|c|c|c|}
\hline $\begin{array}{l}\text { Singer } \\
\text { et al. }\end{array}$ & USA & $\begin{array}{l}\text { Primary } \\
\text { complex } \\
\text { motor } \\
\text { stereotypies } \\
\text { home } \\
\text { behavioral } \\
\text { therapy }\end{array}$ & $\begin{array}{l}36 \text { patients completed home } \\
\text { therapy with DVD } \\
\text { instructions and follow-up } \\
\text { of therapist phone calls and } \\
\text { online scales assessment }\end{array}$ & $\begin{array}{l}\text { Beneficial combination of in- } \\
\text { person and home-based } \\
\text { therapy, importance of careful } \\
\text { patients inclusion to home- } \\
\text { based behavioral therapies }\end{array}$ \\
\hline $\begin{array}{l}\text { Smith } \\
\text { et al. }\end{array}$ & $\begin{array}{l}\text { Australi } \\
\text { a }\end{array}$ & $\begin{array}{l}\text { Telepediatric } \\
\text { consultation } \\
\text { comparison }\end{array}$ & $\begin{array}{l}\text { Among pediatric specialties, } \\
\text { neurology consults of } 2^{\text {nd }} \\
\text { highest score }(10 \%) \text { in } 15 \\
\text { years }\end{array}$ & $\begin{array}{l}\text { Robot videconference systems } \\
\text { in regional wards, mobile } \\
\text { telehealth ENT surveillance } \\
\text { Funding and staff availability } \\
\text { as most challenging aspects }\end{array}$ \\
\hline $\begin{array}{l}\text { Van } \\
\text { Diest et } \\
\text { al. }\end{array}$ & USA & $\begin{array}{l}\text { Adherence in } \\
\text { migrane } \\
\text { treatment } \\
\text { using } \\
\text { electronic } \\
\text { monitoring }\end{array}$ & $\begin{array}{l}56 \text { patients measuring } \\
\text { adherence with electronic } \\
\text { monitoring and self-reports }\end{array}$ & $\begin{array}{l}\text { Higher rate of adherence in } \\
\text { electronic monitoring } 75 \% \\
\text { rather than self-reporting } 64 \% \text {, } \\
\text { higher adherence in } 1 \text { doses } \\
\text { rather than 2, monitoring of } \\
\text { prophylaxis measures }\end{array}$ \\
\hline $\begin{array}{l}\text { Willia } \\
\text { ms et } \\
\text { al. }\end{array}$ & $\begin{array}{l}\text { Guinea, } \\
\text { USA, } \\
\text { Canada }\end{array}$ & $\begin{array}{l}\text { Smartphone } \\
\text { EEG and } \\
\text { remote online } \\
\text { interpretation } \\
\text { of the result }\end{array}$ & $\begin{array}{l}97 \text { patients underwent EEG } \\
\text { examination with } \\
\text { Smartphone Brain Scanner- } \\
2 \text { and compared to the } \\
\text { results obtained with Xltek } \\
\text { technology }\end{array}$ & $\begin{array}{l}\text { Sensitivity of } 51.6 \% \text { and } \\
\text { specificity of } 90.4 \% \text { of the all } \\
\text { types of epileptiform changes } \\
\text { in case of the Smartphone } \\
\text { Brain Scanner-2 }\end{array}$ \\
\hline
\end{tabular}

Pre-pandemic telehealth included primary concerns of inability to consult the specialist due to scarce specialist amount, the aim to reduce the burden of cost of transportation and lost days of work and school for patients and caregivers, as well as to broaden the options for treatment and monitoring of pediatric neurology disorders. In Australia, telemedicine served as the mean to provide clinical, educational and prophylactic interventions among indigenous populations. It has been revealed, that pediatric neurology has been the $2^{\text {nd }}$ most frequent specialization to hold telemedical consultations over 15 years of telehealth monitoring. [8] Research by Gali et al reported $94 \%$ parental and $100 \%$ physician satisfaction from telemedicine interventions among total 61 respondents. [9] Study by Dayal et al discussed the differences between the over 13,000 in-person and over 1,000 telemedicine appointment groups. It has been noted, that telemedicine group came from nonprivate insurance, lower income and lower education. The telemedicine interventions in this study, over the timespan of 8 years since 2009, has been conducted in the remote clinic setting, therefore required patient to travel only to the remote clinic (average transportation time 22 minutes comparing to 157 minutes travel to primary hospital), therefore did not require particular electronic technology from the family; the essential aspect of this setting was the cooperation between the primary physician and consulting neurologists. [4] 
The second study from the same research group of between 378 telemedicine and 3791 inperson patients discovered $57 \%$ higher odds completion of visits and less amount of unplanned hospital encounters among telemedicine group than the in-person group. [10]

Research by Craig at el discussed implementation of telemedicine in remote diagnosis for neonatal encephalopathy, which reduced the unnecessary transfers from tertiary hospitals to specialized clinics and have the potential to limit the instances of separation from the family. [11] The solution was faced with issue of no follow up on the health condition of non-treated infants, no information on the additional examinations and confirmations of the diagnosis was included. Remote diagnosis of epilepsy in Republic of Guinea, presented in study by Williams et al, has been challenged with the use of Smartphone Brain Scanner, a device which enables easier performance of EEG examination in low-income and limited healthcare settings. Comparison between the remote device and standard Xltek examination performed by specialized technician, later followed-up by the specialists in the USA, revealed the sensitivity of $51.6 \%$ and specificity of $90.4 \%$ of the all types of epileptiform changes. [12] These findings seem to be a promising first steps in providing epilepsy diagnostic tools in healthcare systems lacking specialists from the field.

In terms of assessment of rare diseases, in research by Ragbeer et al, one of the previously introduced solutions were "research house calls" - assessment performed by the dispatched specialists in patient's home, which was considered both logistically and economically difficult. Especially progressive neurodegenerative diseases, such as Batten disease, due to lack of access to specialists and difficulties to attend annual meetings and various consultations were considered to benefit positively from the telemedicine interventions. [13] The rare diseases remote management is challenged with the necessity for various electronic devices and setup needed for neurocognitive assessment as well as support from local health practitioners, who may not be familiar with the particular syndrome. It was noted that clinical research of rare diseases could also benefit from telecommunication with the facilitation of consent and enrollment process to trials and evaluations. Another research by Gulati et al assessed the accuracy of pediatric neurology fellow and specialty nurse telephone follow-ups with particular disease-specific questionnaires in epilepsy patients population (West syndrome, Lennox Gastault syndrome, primary generalized epilepsy, cooccurrence of neurocysticercosis and seizures etc). The research revealed nearly $100 \%$ sensitivity and specificity of pediatric neurology fellow and 84-98\% sensitivity and 81-99\% specificity of specialty nurse consultations, who experienced difficulties in assessing semiology of atypical seizures and subjective adverse events, which was explained with the difference in training between the professions. [14] 
Telemedicine was confirmed to be beneficial for home-based therapies in two examples of behavioral therapy for complex motor stereotypies, and cognitive behavioral therapy for persistent post-concussive symptoms in pediatric patients. In case of complex motor stereotypies, DVD-based therapy at home was discussed in Singer et al study as a great addition to in-person therapy; however the importance of assessment of patients prior to enrollment was underlined, due to possible drop out of patients with more severe symptoms of ADHD [15]. Among persistent post-concussive symptoms, emotional issues (depression, anxiety), fatigue and worsening concentration or memory affect greatly the lives of suffering adolescents, which has been confirmed to be successfully treated with home-based CBT therapy, as reported by McCarthy et al. By being taught various relaxation, problem coping and cognitive skills, the telemedicine group of patients achieved significant improvements of results regarding post concussive symptoms (measured with Health Behavior Inventory) and Pediatric Quality of Life. [16] In terms of treatment monitoring, one research from Kroon Van Diest et al conducted an electronic monitoring of compliance to migraine medication and compared it with self-reporting compliance rates. Surprisingly, higher adherence of $75 \%$ with electronic monitoring was observed rather than in self-reporting- 64\%, which was hypothetically related to adolescents considering 2 doses as a full compliance rather than only 1 dose in particular cases. The electronic monitoring and self-monitoring with particular apps have been a quite effective mean of monitoring of the treatment as well as beneficial in the prophylaxis of migraines (limiting triggering events - such as skipping meals, introducing and maintaining exercise in patient's life. [17]

\subsection{Telemedicine in pediatric neurology during SARS-CoV-2 pandemic}

\subsubsection{General recommendations and results of telemedicine introduction}

SARS-CoV-2 pandemic has reprioritized goals of healthcare systems towards COVID-19 infected patients, but also towards prevention of further spread of the virus, especially in the hospital settings among vulnerable patients. This resulted in cancellations and delays of all non-essential interventions and admissions of only emergency nature, potentially risking worsening of chronic, so far stable conditions. National lockdowns and remote labour, schooling, lack of social interactions brought mental health concerns of anxiety, depression and general instability and distortion of life the world once knew. In healthcare systems, the alternative mechanisms had to be introduced, along with the rapid provision of telehealth interventions. In USA, 75\% of National Epilepsy Centers have not experienced telemedicine interventions before pandemic, with $50 \%$ of centers starting implementing ad hoc telemedicine solutions after pandemic started. [3] Similar results have been obtained in international research among respondents from 35 countries, in which $50.5 \%$ of participants reported initiation of telemedicine interventions after pandemic started. [5] In Canadian example from Lee et al of pediatric neurology practice, pre-pandemic telemedicine consultation rate was $4.6 \%$, since the start of pandemic it changed to $96 \%$ of virtual health appointments $(63 \%$ virtual visits via Skype for Business, Zoom, 32.8\% telephone consultations). [18] 
In research from India by Panda et al, effectiveness and feasibility of telemedicine in COVID19 pandemic was assessed. Over 52days, 278 consultations for 153 previously admitted patients were performed by the same physicians as during previous follow-ups. In nearly $44 \%$ of patients significant clinical events were observed (breakthrough seizures, AED and AEDunrelated adverse events, worsening of co-morbidities). The interventions included modification of AED doses, change of medication, hospital referral, ensuring the correct administration of treatment and resolving acute events. $3 \%$ of patients were advised for immediate admission. [19]

It has been noted, that in many countries there were either no telemedicine guidelines or lack of telemedicine guidelines regarding pediatric patients. Pandemic resulted in speeding up of the process of formulation of telehealth recommendations in neurology, particularly "Telemedicine and Remote Care Implementation Guide" by American Academy of Neurology, American Epilepsy Society Telehealth Quick Guide and webinars, "Neurology Exam via Telemedicine" guide by The Child Neurology Society, American Telemedicine Association "Operating Procedures for Pediatric Telehealth" . [3;19;20] In India, Medical Council of India permitted the use of telemedicine, including tools with can provide efficient tele-communication and consultation, such telephone, video equipment, messenger applications, internet-based digital platforms. [19]

Research by Mercuri et al presented the solutions from of an Italian center in Rome, which provides health care for various chronic disease patients ranging from pediatric neurology, rare diseases, to neuromuscular and spina bifida cases. The center created a Contactless health care providing system. This system consists of 3 levels of care depending on patient's needs: basic, intermediate/intermediate plus, and advanced. Basic option includes only video call consultations. Intermediate level expands to multispecialist care, provision of monitoring devices available at patient's home, questionnaires and video tutorials. Intermediate plus includes also nurse or therapist support, tutorials on rehabilitation, gastrostomy or tracheostomy care. In the advanced level, families are equipped with multimodal devices. Devices can send alert to the Listening Centre, which operates 24/7 and dispatch an emergency intervention. [21] It can be considered a very promising solution not only for the times of the pandemic, but also for the future home-based holistic support for pediatric neurology patients.

The satisfaction of parents from telemedicine interventions in the research results ranged between 93-96\%, even when technical challenges occurred. [18;19;22] Among caregivers, telemedicine was proven to reduce anxiety related to consultations, and parents considered having virtual follow-ups in the future as well. Particularly in epilepsy patients group it was contemplated by the parents, that adjustments of medication and counselling are possible to be performed in telephone visit, however telehealth was deliberated to be a difficult mean to establish a doctor-patient relationship between intellectually disabled children. [23] It has been noted by two authors, that minority patients utilized telemedicine interventions less than the general population [24], as well as phone consultations were more common than virtual visits among minorities. [22]. 
These findings suggested the need to address these differences and support the equal provision of telemedicine services, in order to prevent health disparities among various ethnic groups.

The telehealth interventions were positively evaluated by the physicians who, however in a small research group, were very content of their performance of the accurate history and physical examination findings in $82 \%$, and nearly $93 \%$ of patients would receive same recommendations as during in-person consultation according to the participating neurologists. [18] Another small group of respondents assessed the adjustment of treatment and noticing of side effects via telemedicine with mean 3/5 likert scale score, while similarity of virtual gathering of medical history and seizure semiology assessment comparing to in-person consultation was judged with mean 4/5 score. [25] Virtual consultation rather than telephone consultations were preferred. [18;25] In international research by Kuchenbuch et al, $61 \%$ of 172 physicians from 35 countries were satisfied with the virtual clinics, $50.9 \%$ decided on less medication changes in telehealth setting, $65.6 \%$ less frequently ordered EEG, blood tests. $81.2 \%$ of international respondents would like to continue remote consultations postpandemic. [5]

\subsubsection{Disease-specific telemedicine research and considerations}

The study by Ben-Pazi et al presented a very interesting perspective on possible applications of telemedicine in multi-angle and multidisciplinary management of cerebral palsy treatment and prevention of various coexisting conditions. Telemedicine was discussed to be improving accessibility to professionals with tele-clinics, providing continuous therapy, preventing particular conditions with tele-follow ups, and enabling multidisciplinary visits including physicians, therapists, and family. The overall benefit of involvement in participatory medicine would improve the tactics on achieving particular goals and improve patient's quality of life. Among various telemedicine interventions, video-conferencing and phone call follow-ups, as well as the provision of materials, asynchronous visualizations (videos of therapy etc) were vital before synchronous telemedicine interventions could occur. Telehealth would serve both in pandemic conditions as well as a part of continuity of care in the future treatment plans. There have been various challenges noted, primarily revolving around patient and family burden of acquiring video-conferencing skills, possible difficulties in following the online consultation, necessity for various adjustments depending on the visual, auditory, physical difficulties in participating in the consultation, increasing the responsibilities of caregivers with telecommunication etc. Guidelines and improvement of tele-monitoring, especially in terms of hip surveillance and gait recording could significantly improve the quality of the provided consultations. [6] A research letter from Saini et al discussed the importance of high quality videos, which could be beneficial to perform general movement assessment (GMA) for cerebral palsy prognosis in infants. High sensitivity and specificity up to $95 \%$ of GMA convinced the physicians to instruct small group of caregivers on the method of performing the videos of children with hyperbilirubinemia and possible adverse neurodevelopmental concerns. 
After initial telemedicine intervention and diagnostics, introduction of telehealth-based occupational therapy, physiotherapy have been performed. The next step of the study will include the use of high quality videos for neurodevelopmental outcomes assessment and detection of early cerebral palsy markers. [26]

Study by Sattar et al discussed the recommendations for proper virtual health consultations for epilepsy patients. The creation of templates and recommendations for the multidisciplinary team to be engaged fully in telemedical intervention to ensure the quality of care even in these settings should be implemented. Prior to the consultation: links to the meeting should be tested, caregivers should be informed on the telemedicine setting, privacy and confidentiality measures, pre-visit questionnaires on prophylaxis, treatment compliance, quality of life, vitamin D and folic acid supplementation should be disseminated, minimalization of distractions for patient need to be underlined. The algorythm in cases of technical issues should include phone and in-person referral. If applicable and required, home devices for to seizure detection, seizure trackers, applications for self-reporting of seizures, SMS-based epilepsy education system (such as Modular Service Package Epilepsy (MOSES) should be introduced to the management plan. [3]

Plenty of research has focused on the inclusion of telemedicine services among West Syndrome diagnosis and follow-up practice. It has been underlined, that the protection of these patients is crucial in COVID-19 pandemic, due to the poor prognostic markers of coexistence of West Syndrome and respiratory comorbidities. [27] In USA, Child Neurology Society with the Pediatric Epilepsy Research Consortium developed infantile spasms guidelines as a crisis standard of care. The guidelines involved telemedicine in the possible algorythm - initial visit performed via telemedicine, asynchronous data of videos done by patient's parents. If possible, outpatient EEG should be performed, followed by MRI if the result is unclear. The follow up consultations were advised to be held via telehealth weekly (at least). [7] These guidelines were followed up by South Asian West Syndrome Research Group, with suggestions for tele-epileptology and telerehabilitation of West syndrome individuals. [27] In South Asia, facilities may experience lack of telemedicine technology, therefore in these emergency setting smartphone based interventions should be developed. [27;28] Child neurologists should closely work with local health providers in terms of performing diagnostic tests and initial evaluation of the etiology. Due to limited amount of pediatric neurologists, educational conferences and video learning modules should be available for local pediatricians to facilitate better detection of West Syndrome in pediatric population. It has been also advised to held tele-consultations to assess compliance with therapy and the effectivenes of treatment in days 7,14,30,42,60,90 after treatment introduction and every 3 months afterwards. [28]

Ketogenic diet has been considered as one of possible interventions in drug-resistant epilepsy, which in non-pandemic setting was normally initiated during hospital admission. Two research papers have been discussing introduction of ketogenic diet in home-setting, as well as follow-up on patients with means of telehealth. 
Study by Kossoff et al presented 4 pediatric case reports on possible initiation and monitoring of ketogenic diet in times of pandemic. The patients have been equipped with educational video and written materials including specialized recipes by dieticians, home kit of gram scale, urine ketone strips, vitamins as well as online classes via Zoom. Second option discussed shortened time of admission to start the diet (1-2days), followed up by online process in later days. Follow-up virtual visits have also been scheduled. The study confirmed successful implementation of ketogenic diet in virtual settings and improvements in cognitive skills, reduced seizure frequency. [29] In another research by Semprino et al, the virtual ketogenic diet introduction and follow-up has been successfully introduced to population of low financial resources via Whatsapp. 54 families have been included in the assessment, which revealed 96,3\% satisfaction from the work of ketogenic diet team, social support network (group of parents) has been proven beneficial to $90 \%$ of participants, $72.2 \%$ of respondents would recommend telemedicine in non-pandemic situation. The instructions on meal preparation was easy to follow for $65.2 \%$, complex but manageable for $30.4 \%$, measuring ketonemia/ketonuria easy for $67.9 \%$, complex byt manageable for $24.5 \%$, high level of satisfaction from the ketogenic diet team 96.3\%. [30]

One case report discussed the change of adherence to obstructive sleep apnea [OSA] pediatric patient treatment with telemedicine. Telehealth cloud-stored data records showed lack of compliance to treatment during lockdown. The parents of the patient were not aware of the situation, however after telemedicine intervention and re-education about consequences and possible comorbities, the post 1-week follow up showed $100 \%$ of compliance. [31]The follow-up period has been relatively short, however the report may induce a possible change in follow-up and monitoring of compliance to various therapies in pediatric neurology population.

Telemedicine found its application in teleneuropsychology in terms of pre-surgical assessment and as part of treatment procedures. In research by Nussbaum et al, an algorythm regarding virtual/hybrid format of evaluation has been created, depending on the importance of neuropsychological examination on surgical decision making and planning and the ability of the patient to participate in virtual consultation. If the assessment could contribute mostly to long-term outcomes only, rather than surgical planning, virtual observations and parent questionnaires were suggested; if the assessment was vital to immediate surgical decisionmaking or planning, depending on patient's abilities, the assessment has been performed virtual, in-person or hybrid (if more clearance is needed after virtual consultation). A patient who participated in the hybrid testing expressed that the in-person evaluation has been subjectively better for them, since it was easier to focus and easier to have contact with the specialist. The psychologists underlined various challenges with telemedical assessment, primarily associated with provision of tests which did not need specialized equipment or manipulatives, inability to control the environment of the assessment, lower sensitivity of body language or eye contact, screen fatigue of the examiner etc. [32] In case of neuropsychology treatment, a study by Taddei et al conducted fully telemedical services beginning with initiation of the virtual visit appointment with phone call, video calls using MS Teams, ending with a follow up with Telemedicine Satisfaction Questionnaire. 
In this study $93 \%$ of patients were able to be reached (challenges with electronic devices, language barriers, familial issues have been noted as reasons for lack of contact); the caregivers were highly satisfied with the telemedicine services with a mean score of 4.55/5. [33]

Telemedicine has been discussed to be beneficial for the diagnosis of inborn errors of metabolism (IEM), in which urgent treatment process is crucial for proper future development of the still growing CNS. In the commentary by Elmonem et al, among internationally interviewed 16 centers for IEM, 3 centers have previous experience in teleservices, and 69\% of centers established online communication and phone follow-ups for the patients. The possibility to send the dry blood spots for the analysis and obtain necessary educational materials via asynchronous means were additionally provided. [34]

Studies have been also discussing the introduction of telehealth in pain management practice. In Canadian experience, Perez et al described various limited telehealth interventions included in the services since 2012, such as clinical video visit, nurse-led phone follow-up on symptom management, as well as unscheduled emergency calls. Since the beginning of the pandemic, the telephone follow-ups rate increased from $30 \%$ to $300 \%$, the pediatric pain clinic switched to telemedicine services only. The institution introduced training on videoconferencing platforms - educational videos, video calls with secretary, an algorythm on using various platforms and encrypted meetings depending on the confidentiality necessities and setting, as well as crucial aspect video etiquette - presenting the physician's id, conduction of identification of the patient (with eg. government photo id when video is used). The study included various examples of possible remote examinations depending on the syndrome, with auscultation and percussion to be either irrelevant or desirable but not feasible options in remote setting. A survey on satisfaction among pediatric patients in a small group showed that they were satisfied with the physician's performance of the visit via telemedicine. It has been also debated, that with the development of the technologies, the pain management, diagnosis and therapy can be virtually implemented with use of high definition 3D, 3D holograms which can be touched, felt and behave, augmented reality options etc. [35]

Study by Bikson et al discussed the advancements in tele-neuromodulation following the pandemic. Tele-neuromodulation has been considered as a promising course of novel therapeutic solutions for patients with limited accessibility to the services based on mobility, location, financial issues etc. The adult patients suffering from multiple sclerosis, depression, stroke complications, have been already benefiting from the tele-neuromoducation interventions. SARS-CoV-2 pandemic resulted in huge changes for the neuromodulation research and monitoring, particularly in adaptation of trial protocols to minimize the contact, including e-consent and remote enrollment, remote collection of data. The home setting trials required shipping of tDCS kits with the device, electrodes, preconfigured laptop, headset, outcomes survey, equipment for daily exercises. A trial particularly aimed for pediatric population has commenced for tDCS therapy in home-setting for patients with perinatal stroke and resultant cerebral palsy. [36] 
Telehealth services have been also evaluated from the perspective of research in times of pandemic in 4 of the reviewed articles. One research by Pasca et al described the impact of the pandemic on a group of 23 patients suffering from epilepsy and neuropsychiatric comorbidities, which was performed with telephone consultations with the caregivers, answering the Child Behaviour Checklist questionnaire and Parenting Stress-Index Short Form Questionnaire. The follow-up has been performed just in the beginning of the pandemic (April-May 2020), however the authors discussed a more long-term intervention for the future, which would be particularly beneficial for this patient group. [37] In international study by Volkers et al on impact of the pandemic on epilepsy research, the International League Against Epilepsy questionnaire through the qualitative methods discovered the increased productivity of online working due to better focus, simultaneous document sharing, the opportunity for remote reviews, online recruitments and assessments, increased data collection via medical records and databases. It has been quite surprising, that until pandemic in some countries the virtual meetings were not accepted in the research community, however it changed due to the public health emergency. The disadvantages of the current situation for research has been described as the cessation of spontaneous discussions, inability to establish networking and partnerships, which are more efficiently created in person. "Science is based on communication", and a part of the communication has been lost due to the social distancing restrictions. [38] Study on TMS research by Bikson et al found potential opportunities for telecommunication to obtain new skills, design new research, re-analyze currently obtained data, follow-up on adverse events. It has been reported, however, that remote work may be challenging for the individuals requiring specialized hardware and protected data setting. [36] In another international study by Kuchenbuch et al 172 physicians from 35 countries, majority (62\%) pediatric neurologists, evaluated the use of telehealth in scientific settings. around $45.2 \%$ of respondents were satisfied with the scientific meetings held virtually, and $54.7 \%$ would continue the virtual conferences after the pandemic. The results of satisfaction and sustaining the virtual practice in scientific meetings has been the least favorable comparing to satisfaction from remote clinics $(61 \%)$, and remote teaching $(56,7 \%) .[5]$

The same study discussed challenges in online medical education during COVID-19 pandemic. For $84.6 \%$ of respondents educational activities turned to online format. Most of the disadvantages of the remote labour was related to the online teaching, in which specialists expressed the lack of immediate feedback, including the non-verbal communication, to be unfavorable for holding educational activities. 51.5\% physicians considered students to be satisfied with online classes, and $62.9 \%$ of respondents would consider sustaining remote educational activities in the post-pandemic future. [5] 
4.3 Comparison of pre-pandemic and pandemic application of telehealth in pediatric neurology

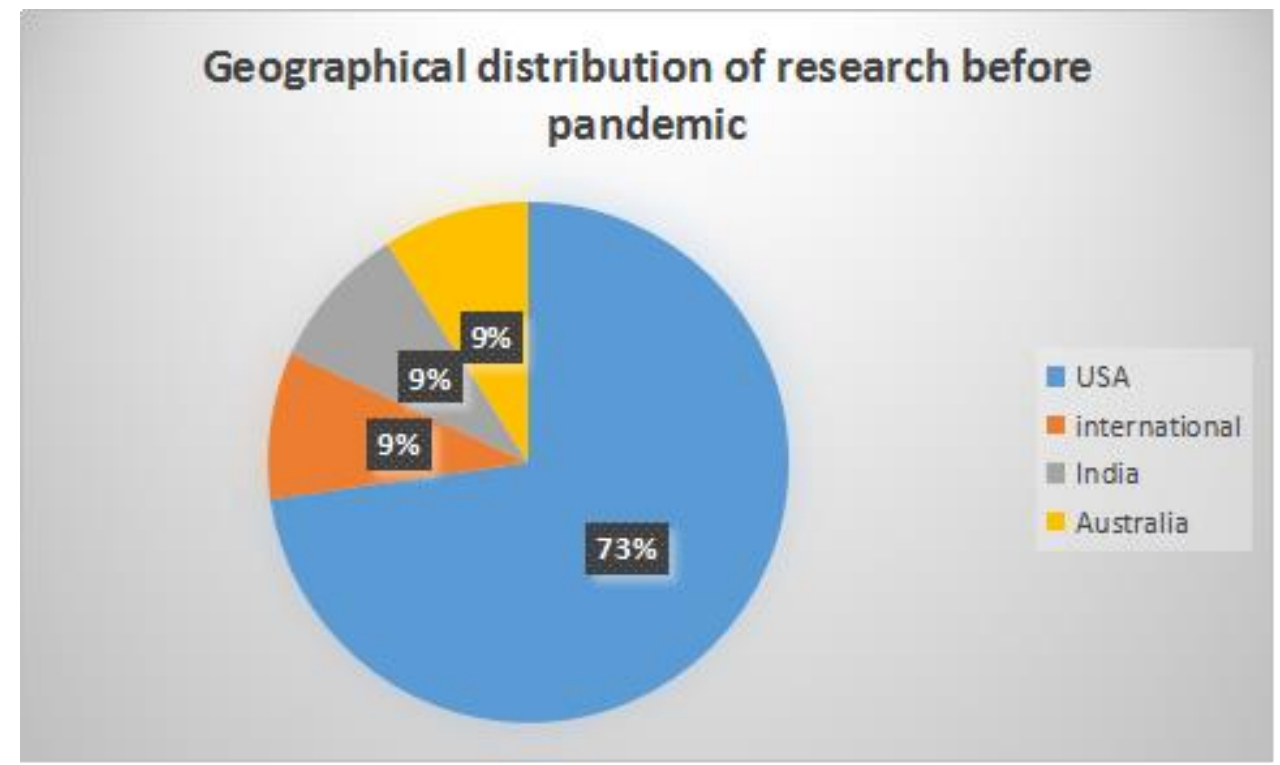

Graph 1.Geographical distribution of research before the pandemic. Prepared by authors.

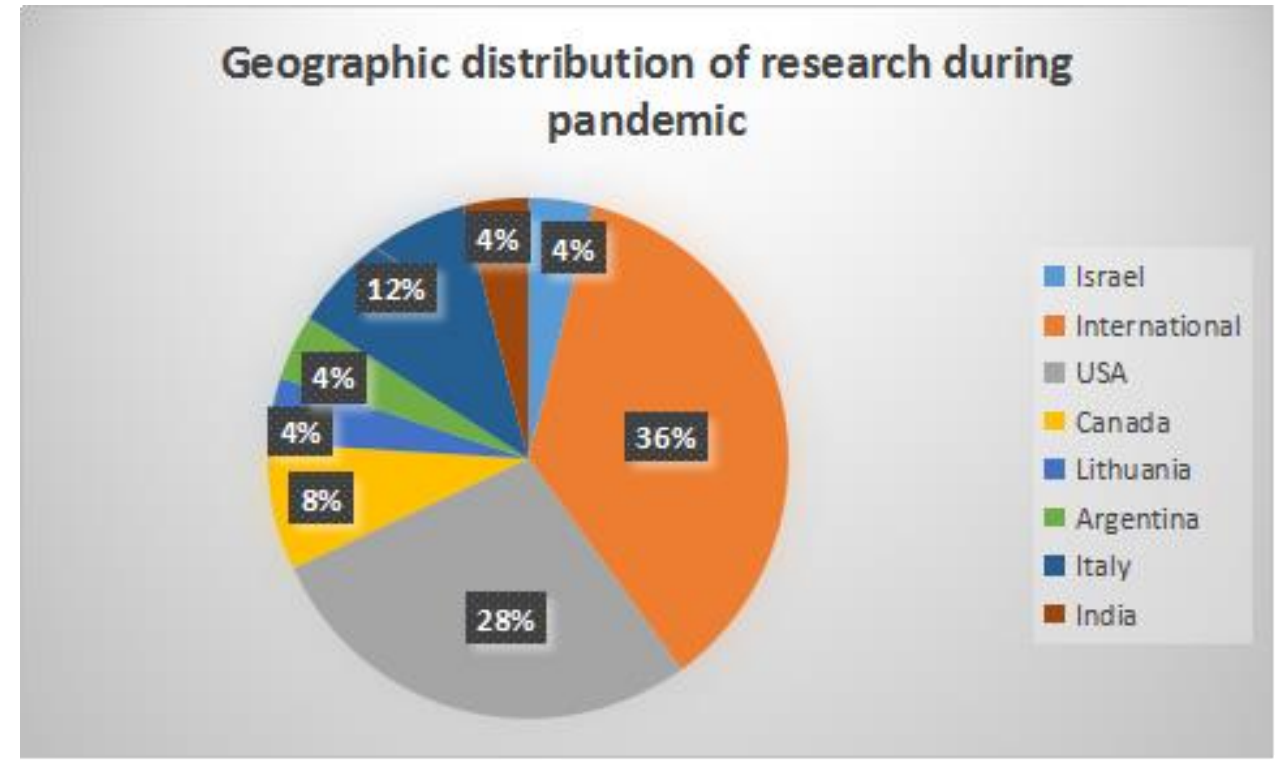

Graph 2.Geographical distribution of research during the pandemic. Prepared by authors.

Our analysis discovered over $200 \%$ of increase in the research regarding telemedicine in pediatric neurology after the start of the SARS-CoV-2 pandemic. It has been assessed, that most of the research before the pandemic has been held in USA and singular studies have been conducted in Australia, India and internationally. Comparing the research held during pandemic, the majority of cooperation has been conducted internationally, with USA and Italy being the second and third most active research sites regarding telemedicine implementation. 
It is important to note that USA and Italy have been among one of the most heavily impacted countries by this public emergency, therefore it is understandable that such interventions were assessed with higher urgency. Pandemic increased the meaning of international cooperation in telemedicine efforts, and sharing the best practices to support other entities in successful virtual health implementation.

Regarding topics discussed in the research, in pre-pandemic studies, $45 \%$ of the research focused on the assessment of implementation, group characteristics, satisfaction from services, while $55 \%$ of studies discussed the interventions tailored towards specific diseases (epilepsy, migraine, primary complex motor stereotypies, neonatal encephalopathy, Batten disease, postconcussive symptoms). In research held during the pandemic, $36 \%$ of research discussed good practices, guidelines, efficiency, satisfaction from the services, while $64 \%$ of research discussed the implications for particular syndromes (6 studies focused on epilepsy, particularly West Syndrome, ketogenic diet; 2 studies discussed cerebral palsy, 3 studies described research in pediatric neurology during pandemic, 2 studies focused on teleneuropsychology, singular studies on pain management, OSA, IEM and teleneuromodulation have been found). Among major differences between pre-pandemic and pandemic-research, increase in international cooperation and discussion of not only medical, but also scientific and academic impact of the pandemic could be noted.

\section{DISCUSSION}

The presented state of art regarding telemedicine in pediatric neurology revealed significant increase of interest in provision of telehealth services in this specialization. It was found to be beneficial in fields of diagnosis, introduction of treatment, continuous rehabilitation, follow-up on treatment compliance and pharmacoresistant cases; it allowed multidisciplinary teams to discuss the best options for the patients, impacted positively the productivity and creativity in research. Telehealth supported the disadvantaged caregivers and patients in decreasing the non-medical costs of healthcare and many challenges for patients families which were the result of the in-person visits. [20] Many of the authors discuss possible inclusion of the newest interventions in non-pandemic setting. Despite having a destructive effect on the in-person daily communication, pandemic encouraged international cooperation and sharing best practices among healthcare, which unites the efforts of professionals in these difficult times. Current telehealth interventions are, however, far from ideal. Primary concerns revolve around ethical dilemmas of data security, privacy and confidentiality of the consultations. [6] In case of adolescent patients, the privacy and concerns which they may do not want to share with their parents cannot be secured in some instances. [3] There is always a possibility of technology malfunction, which would hinder the efforts and prevent from detection of important information. The concern of possible deepening of the disparities due to lack of technology accessibility among lower income households, as well as digital illiteracy may prevent the disadvantaged population to access healthcare services. In these cases, less private smartphone interventions can be the only option to receive telemedicine care. Various concerns related to the process of conducting virtual visits were voiced, in particular regarding the physician-patient relationship, limitation for proper physical examination and ensuring the quality of care. 
Physician-patient relationship based on trust is crucial for treatment compliance, which may be difficult to be established for first-time consultations held virtually. [3] Secondly, neurological examination cannot be performed fully online- muscle tone assessment, sensory deficits, subtle weakness, accurate head circumference measurements, Woods lamp examination are impossible to be performed in virtual setting.[3;39] It has been noted, that breaking sudden news on a new diagnosis may have various impact on the families, which could be better assessed and managed during in-person visits. Telehealth, as a relatively new intervention, is unfavorably assessed by insurance companies and employers - these economic concerns should be properly address in current situation. Despite these dilemmas, healthcare over the years has improved security and privacy settings, established algorythms to protect the already existing ethical and legal mechanisms such as informed e-consent, proper patient identification, as well as introduced various options which may not be possible during inperson meetings due to time constraints, such as tele-prophylaxis, satisfaction assessments etc. The future holds possible solutions for currently not fully effective physical examinations with augmented reality, $3 \mathrm{~d}$ holograms, remote patient monitoring. [36]

\section{CONCLUSIONS}

Telehealth has been successfully supporting healthcare system in pediatric neurology. Before SARS-CoV-2 pandemic, the primary goal was to expand the reach of healthcare services for the broader geographic locations and decrease financial burdens. Since the beginning of the pandemic, the expansion of telehealth services brought new solutions for the treatment, rehabilitation, education and research in pediatric neurology, with high satisfaction of patients and professionals from delivered consultations. In the post-pandemic future, we believe that many of these inventions will become either a substitution for pre-pandemic mechanisms, or will aid the in-person consultations with virtual follow-ups, increasing the amount of beneficial interventions with home-treatment or rehabilitation, and will allow to reach more individuals with prophylaxis campaigns.

\section{References:}

1. Shaw, D. K. (2009). Overview of Telehealth and Its Application to Cardiopulmonary Physical Therapy. Cardiopulmonary Physical Therapy Journal, 20(2), 13.

2. Srinivasan, R., Ben-Pazi, H., Dekker, M., Cubo, E., Bloem, B., Moukheiber, E. et al. (2020). Telemedicine for Hyperkinetic Movement Disorders. Tremor and Other Hyperkinetic Movements, 10(0). https://doi.org/10.5334/tohm.534

3. Sattar, S., \& Kuperman, R. (2020). Telehealth in pediatric epilepsy care: A rapid transition during the COVID-19 pandemic. Epilepsy \& Behavior, 111, 107282. https://doi.org/10.1016/j.yebeh.2020.107282

4. Dayal, P., Chang, C. H., Benko, W. S., Ulmer, A. M., Crossen, S. S., Pollock, B. H., et al. (2019). Appointment completion in pediatric neurology telemedicine clinics serving underserved patients. Neurology: Clinical Practice, 9(4), 314-321. https://doi.org/10.1212/CPJ.0000000000000649

5.Kuchenbuch, M., D’Onofrio, G., Wirrell, E., Jiang, Y., Dupont, S., Grinspan, Z. M., et al. (2020). An accelerated shift in the use of remote systems in epilepsy due to the COVID-19 pandemic. Epilepsy \& Behavior, 112, 107376. https://doi.org/10.1016/j.yebeh.2020.107376 
6. Ben-Pazi, H., Beni-Adani, L., \& Lamdan, R. (2020). Accelerating Telemedicine for Cerebral Palsy During the COVID-19 Pandemic and Beyond. Frontiers in Neurology, 11, 746. https://doi.org/10.3389/fneur.2020.00746

7. Grinspan, Z. M., Mytinger, J. R., Baumer, F. M., Ciliberto, M. A., Cohen, B. H., Dlugos, D. J., et al. (2020). Management of Infantile Spasms During the COVID-19 Pandemic. Journal of Child Neurology, 35(12), 828-834. https://doi.org/10.1177/0883073820933739

8. Smith, A. C., Armfield, N. R., Coulthard, M. G., Williams, M. L., \& Caffery, L. J. (2020). Queensland Telepaediatric Service: A Review of the First 15 Years of Service. Frontiers in Digital Health, 2, 587452. https://doi.org/10.3389/fdgth.2020.587452

9. Gali, K., Joshi, S., Hueneke, S., Katzenbach, A., Radecki, L., Calabrese, T. Et al. (2020). Barriers, access and management of paediatric epilepsy with telehealth. Journal of Telemedicine and Telecare, 1357633X2096953. https://doi.org/10.1177/1357633X20969531

10. Dayal, P., Chang, C. H., Benko, W. S., Pollock, B. H., Crossen, S. S., Kissee, J. Et al. (2019). Hospital Utilization Among Rural Children Served by Pediatric Neurology Telemedicine Clinics. JAMA Network Open, 2(8), e199364. https://doi.org/10.1001/jamanetworkopen.2019.9364

11. Craig, A. K., McAllister, L. M., Evans, S., \& Melendi, M. E. (2021). Telemedicine consults to assess neonatal encephalopathy are feasible in the neonatal intensive care unit. Journal of Perinatology, 41(6), 1519-1521. https://doi.org/10.1038/s41372-020-00828-3

12. Williams, J. A., Cisse, F. A., Schaekermann, M., Sakadi, F., Tassiou, N. R., Hotan, G. C., et al. (2019). Smartphone EEG and remote online interpretation for children with epilepsy in the Republic of Guinea: Quality, characteristics, and practice implications. Seizure, 71, 93-99. https://doi.org/10.1016/j.seizure.2019.05.025

13. Ragbeer, S. N., Augustine, E. F., Mink, J. W., Thatcher, A. R., Vierhile, A. E., \& Adams, H. R. (2016). Remote Assessment of Cognitive Function in Juvenile Neuronal Ceroid Lipofuscinosis (Batten disease): A Pilot Study of Feasibility and Reliability. Journal of Child Neurology, 31(4), 481-487. https://doi.org/10.1177/0883073815600863

14. Gulati, S., Shruthi, N. M., Panda, P. K., Sharawat, I. K., Josey, M., \& Pandey, R. M. (2020). Telephone-based follow-up of children with epilepsy: Comparison of accuracy between a specialty nurse and a pediatric neurology fellow. Seizure, 83, 98-103. https://doi.org/10.1016/j.seizure.2020.10.002

15. Singer, H. S., Rajendran, S., Waranch, H. R., \& Mahone, E. M. (2018). Home-Based, TherapistAssisted, Therapy for Young Children With Primary Complex Motor Stereotypies. Pediatric Neurology, 85, 51-57. https://doi.org/10.1016/j.pediatrneurol.2018.05.004

16. McCarty, C. A., Zatzick, D. F., Marcynyszyn, L. A., Wang, J., Hilt, R., Jinguji, T., et al. (2021). Effect of Collaborative Care on Persistent Postconcussive Symptoms in Adolescents: A Randomized $\begin{array}{lllll}\text { Clinical Trial. JAMA Network } & \text { Open, } 210207 .\end{array}$ https://doi.org/10.1001/jamanetworkopen.2021.0207

17. Kroon Van Diest, A. M., Ramsey, R., Aylward, B., Kroner, J. W., Sullivan, S. M., Nause, K., et al. (2016). Adherence to Biobehavioral Recommendations in Pediatric Migraine as Measured by Electronic Monitoring: The Adherence in Migraine (AIM) Study. Headache: The Journal of Head and Face Pain, 56(7), 1137-1146. https://doi.org/10.1111/head.12836

18. Lee, J., Schrader, D., Boelman, C., Huh, L., \& Connolly, M. B. (2021b). Rapid Implementation of Virtual Health in a Pediatric Neurology Practice During COVID-19. Canadian Journal of Neurological 
Sciences / Journal Canadien Des Sciences Neurologiques, 48(4), 575-577. https://doi.org/10.1017/cjn.2020.241

19. Panda, P. K., Dawman, L., Panda, P., \& Sharawat, I. K. (2020b). Feasibility and effectiveness of teleconsultation in children with epilepsy amidst the ongoing COVID-19 pandemic in a resourcelimited country. Seizure, 81, 29-35. https://doi.org/10.1016/j.seizure.2020.07.013

20. Guido-Estrada, N., \& Crawford, J. (2020). Embracing Telemedicine: The Silver Lining of a Pandemic. Pediatric Neurology, 113, 13-14. https://doi.org/10.1016/j.pediatrneurol.2020.08.017

21. Mercuri, E., Zampino, G., Morsella, A., Pane, M., Onesimo, R., Angioletti, C., et al. (2021). Contactless: A new personalised telehealth model in chronic pediatric diseases and disability during the COVID-19 era. Italian Journal of Pediatrics, 47(1), 29. https://doi.org/10.1186/s13052-021-00975$\mathrm{z}$

22. Rametta, S. C., Fridinger, S. E., Gonzalez, A. K., Xian, J., Galer, P. D., Kaufman, M., et al. (2020). Analyzing 2,589 child neurology telehealth encounters necessitated by the COVID-19 pandemic. Neurology, 95(9), e1257-e1266. https://doi.org/10.1212/WNL.0000000000010010

23. Klotz, K. A., Borlot, F., Scantlebury, M. H., Payne, E. T., Appendino, J. P., Schönberger, J., \& Jacobs, J. (2021). Telehealth for Children With Epilepsy Is Effective and Reduces Anxiety Independent of Healthcare Setting. Frontiers in Pediatrics, 9, 642381. https://doi.org/10.3389/fped.2021.642381

24. Fitzgerald, M. P., Kaufman, M. C., Massey, S. L., Fridinger, S., Prelack, M., Ellis, C., et al. (2021). Assessing seizure burden in pediatric epilepsy using an electronic medical record-based tool through a common data element approach. Epilepsia, 62(7), 1617-1628. https://doi.org/10.1111/epi.16934

25. Puteikis, K., \& Mameniškienè, R. (2021). Epilepsy care and COVID-19: A cross-sectional online survey from Lithuania. Acta Neurologica Scandinavica, 143(6), 666-672. https://doi.org/10.1111/ane.13409

26. Saini, L., Madaan, P., Bhagwat, C., \& Einspieler, C. (2021). Home-Videos for Neurodevelopmental Follow-Up of High-Risk Infants during COVID-19 Pandemic: A Simple and Inexpensive Tool. Journal of Tropical Pediatrics, 67(1), fmaa088. https://doi.org/10.1093/tropej/fmaa088

27. Sahu, J. K., Madaan, P., Chand, P., Kumar, A., Linn, K., Mynak, M. L. Et al (2020). Management of West syndrome during COVID-19 pandemic: A viewpoint from South Asian West Syndrome Research Group. Epilepsy Research, 167, 106453. https://doi.org/10.1016/j.eplepsyres.2020.106453

28. Madaan, P., Sahu, J. K., Wanigasinghe, J., Fatema, K., Linn, K., Lhamu Mynak, M., et al. (2021). Teleneurology based management of infantile spasms during COVID-19 pandemic: A consensus report by the South Asia Allied West syndrome research group. Epilepsy \& Behavior Reports, 15, 100423. https://doi.org/10.1016/j.ebr.2020.100423

29. Kossoff, E. H., Turner, Z., Adams, J., Bessone, S. K., Avallone, J., McDonald, T. J. W., et al. (2020). Ketogenic diet therapy provision in the COVID-19 pandemic: Dual-center experience and recommendations. Epilepsy \& Behavior, 111, 107181. https://doi.org/10.1016/j.yebeh.2020.107181

30. Semprino, M., Fasulo, L., Fortini, S., Martorell Molina, C. I., González, L., Ramos, P. A., et al. (2020). Telemedicine, drug-resistant epilepsy, and ketogenic dietary therapies: A patient survey of a pediatric remote-care program during the COVID-19 pandemic. Epilepsy \& Behavior, 112, 107493. https://doi.org/10.1016/j.yebeh.2020.107493 
31. Naime, S., Weiss, M., \& Nino, G. (2021). Effects of COVID-19 pandemic on adherence to obstructive sleep apnea therapy: A case report. Clinical Case Reports, 9(1), 12-14. https://doi.org/10.1002/ccr3.3363

32. Nussbaum, N. L., Young, S. R., DeLeon, R. C., Engelmann, M. L., \& Schraegle, W. A. (2021). The future is now: Pediatric neuropsychological presurgical epilepsy evaluation in the age of COVID19. Epileptic Disorders, 23(2), 274-280. https://doi.org/10.1684/epd.2021.1274

33. Taddei, M., \& Bulgheroni, S. (2020). Facing the real time challenges of the COVID-19 emergency for child neuropsychology service in Milan. Research in Developmental Disabilities, 107, 103786. https://doi.org/10.1016/j.ridd.2020.103786

34. Elmonem, M. A., Belanger-Quintana, A., Bordugo, A., Boruah, R., Cortès-Saladelafont, E., Endrakanti, M. et al. (2020). The impact of COVID-19 pandemic on the diagnosis and management of inborn errors of metabolism: A global perspective. Molecular Genetics and Metabolism, 131(3), 285288. https://doi.org/10.1016/j.ymgme.2020.09.004

35. Perez, J., Niburski, K., Stoopler, M., \& Ingelmo, P. (2021). Telehealth and chronic pain management from rapid adaptation to long-term implementation in pain medicine: A narrative review. PAIN Reports, 6(1), e912. https://doi.org/10.1097/PR9.0000000000000912

36. Bikson, M., Hanlon, C. A., Woods, A. J., Gillick, B. T., Charvet, L., Lamm, C., et al. (2020). Guidelines for TMS/tES clinical services and research through the COVID-19 pandemic. Brain Stimulation, 13(4), 1124-1149. https://doi.org/10.1016/j.brs.2020.05.010

37. Pasca, L., Zanaboni, M. P., Grumi, S., Totaro, M., Ballante, E., Varesio, C. et al. (2021). Impact of COVID-19 pandemic in pediatric patients with epilepsy with neuropsychiatric comorbidities: A $\begin{array}{llllll}\text { telemedicine evaluation. } & \text { Epilepsy } \& \quad \text { Behavior, } & 115, & 107519 .\end{array}$ https://doi.org/10.1016/j.yebeh.2020.107519

38. Volkers, N., Wiebe, S., Asadi-Pooya, A. A., Balagura, G., Gómez-Iglesias, P., Guekht, A.,et al. (2021b). The initial impact of the SARS-CoV-2 pandemic on epilepsy research. Epilepsia Open, 6(2), 255-265. https://doi.org/10.1002/epi4.1241

39. Wirrell, E. C., Grinspan, Z. M., Knupp, K. G., Jiang, Y., Hammeed, B., Mytinger, J. R., et al. (2020). Care Delivery for Children With Epilepsy During the COVID-19 Pandemic: An International Survey of Clinicians. Journal of Child Neurology, 35(13), 924-933. https://doi.org/10.1177/0883073820940189 